\title{
Marta Szpatowicz
}

Uniwersytet Szczeciński

(iD) http://orcid.org/0000-0001-7130-9126

\section{Cierpienie i pocieszenie w slashu}

\section{Hurt and Comfort in slash}

\begin{abstract}
This article aims to describe one of the fanfiction genres - hurt/ comfort, which most often occurs within slash, i.e. the type of texts that focus on romantic/erotic relationships between two male characters. In hurt/comfort stories, one of the heroes is subjected to mental or physical suffering, while the other takes care of the wounded or the sick one. Pain and life-threatening situations allow the heroes to get closer to each other, make them realize a strong attachment, and build intimacy between them. Such texts can be read as criticism of traditional concepts of masculinity related to patriarchal culture.
\end{abstract}

Key words: cultural theory of literature, fanfiction, slash, hurt/comfort

Streszczenie: Celem niniejszego artykułu jest opisanie jednego z gatunków fanfikcji (twórczości literackiej fanów) - hurt/comfort, który najczęściej występuje w obrębie slashu, czyli takiego rodzaju tekstów, które skupiają się na relacjach romantycznych/erotycznych między dwoma męskimi bohaterami. W hurt/comfort jedna $\mathrm{z}$ postaci zostaje poddana cierpieniom psychicznym lub fizycznym, druga otacza rannego czy chorego opieką. Ból i sytuacje zagrażające zdrowiu czy życiu pozwalają zbliżyć się do siebie bohaterom, uświadomić silne przywiązanie, zbudować między nimi intymność. Tego typu teksty mogą być odczytywane jako krytyka tradycyjnych koncepcji męskości związanych $\mathrm{z}$ kulturą patriarchalną.

Słowa kluczowe: kulturowa teoria literatury, fanfikcja, slash, hurt/comfort 


\section{Fanfikcja, kanon, fanon}

W 1992 roku Camille Bacon-Smith w książce Enterprising Women: Television Fandom and the Creation of Popular Myth określiła hurt/ comfort (H/C) jako „serce” fandomu'. Na gruncie polskich fan studies gatunek ten jednak rzadko stanowi główny przedmiot rozważań. Wzmianki o nim towarzyszą zwykle analizom innego gatunku fanfikcji (twórczości literackiej fanów) - slashu, z którym hurt/comfort często współwystępuje. Hurt/comfort proponuje niestereotypowe rozwiązania fabularne $\mathrm{w}$ przedstawianiu relacji intymnych, dekonstruując modele genderowe obowiązujące w świecie pozaliterackim.

Fanfikcja to taki rodzaj pisarstwa, w którym fan-autor tworzy własne narracje, opierając się na już istniejących tekstach kultury (filmach, serialach, książkach, komiksach, grach komputerowych itp.), przejmując z ulubionego utworu interesujące go elementy, najczęściej postacie. Stopień zależności tych tekstów od dzieła źródłowego, czyli tzw. kanonu², jest różny. Obok niego równie ważny jest fanon, który stanowi efekt fanowskich interpretacji kanonu. Na fanon składają się treści często powtarzające się $\mathrm{w}$ ramach twórczości danego fandomu ${ }^{3}$, a niewystępujące w utworze źródłowym (lub mające znikome podstawy w kanonie) ${ }^{4}$. Do fanonu może wejść każdy element, który zostanie zaakceptowany przez większość wspólnoty, tzn. tak rozpowszechniony, że uznany za stały składnik danego uniwersum. Zdarza się, że fanfikcja bazuje także na wizerunkach rzeczywiście istniejących osób (nie postaci fikcyjnych): aktorów, pisarzy, piosenkarzy, sportowców itd. Tego rodzaju teksty tworzą jednak osobny (kontrowersyjny) gatunek - tzw. RPF (real person fiction), w którym mieści się również m.in. RPS (real person slash) ${ }^{5}$. Fani za swoją pracę nie pobierają wynagrodzenia, ich działalność nie jest bowiem częścią komercyjnego obiegu, co ma związek m.in. z prawem autorskim ${ }^{6}$.

${ }^{1}$ C. Bacon-Smith: Enterprising Women. Television Fandom and the Creation of Popular Myth. Philadelphia 1992.

${ }^{2}$ Kanon to wszystkie wydarzenia, postacie, elementy przedstawione w tekście źródłowym. Do kanonu mogą zostać także włączone wypowiedzi autorów oryginalnych, które w jakiś sposób uzupełniają, tłumaczą treści zawarte w dziele.

${ }^{3}$ Fandom to społeczność fanowska skupiona wokół danego tekstu kultury czy też gatunku, zespołu muzycznego, znanych osób.

${ }^{4}$ K. Busse, K. Hellekson: Fan Fiction and Fan Communities in the Age of the Internet. New Essays. Jefferson, North Carolina 2006, s. 9.

${ }^{5}$ Niektóre strony internetowe gromadzące fanfikcję zakazują publikowania tego typu twórczości, np. FanFiction.net.

${ }^{6}$ A. Kobus, J. Krzyżanowska: Stownik fandomu i fanfiction. W: Fandom. Fanowskie modele odbioru. Red. A. Kobus. Toruń 2018, s. 366-367. 
Początki fanfikcji sięgają czasów przed powstaniem ogólnoświatowej sieci komputerowej. Obecnie jednak fani przejawiają swoją aktywność przede wszystkim w internecie, który umożliwił im dzielenie się swoją twórczością na znacznie większą skalę. $\mathrm{Na}$ jednej z popularniejszych, międzynarodowych stron gromadzących fikcje fanowskie, Archive of Our Own, znajduje się aktualnie ponad 6 milionów prac, powstałych $\mathrm{w}$ ramach ponad 38 tysięcy różnych fandomów ${ }^{7}$. A jest to tylko jedno $\mathrm{z}$ wielu miejsc publikowania tego rodzaju twórczości.

Ze względu na ogromną liczbę tekstów, istotne są wykształcone i stosowane przez fanów sposoby ich klasyfikowania, z czym wiąże się także bogata, specyficzna nomenklatura. Nazwy powszechnie znane, przyjęte we wszystkich fandomach mają przede wszystkim umożliwiać wyszukiwania pożądanych treści. Małgorzata Lisowska-Magdziarz pisała, że wypracowywane przez fanów folksonomie są zorientowane wyłącznie na komunikację wewnętrzną ${ }^{8}$. Ich celem nie jest formułowanie precyzyjnych systemów genologicznych, lecz bezpośrednie zaspokajanie bieżących potrzeb fanów ${ }^{9}$.

\section{gen, het, slash}

W literaturze przedmiotu najczęściej spotyka się podział fanfikcji na trzy podstawowe gatunki: gen, het oraz slash ${ }^{10}$. Typologia ta odpowiada wyróżnionemu przez Aldonę Kobus w książce Fandom. Fanowskie modele odbioru sposobowi klasyfikowania fikcji fanowskich opartemu na treści, który występuje równolegle do systematyki opartej na formie ${ }^{11}$. Pierwszy podział może odwoływać się do trzech aspektów tekstu: wiodących pairingów, czyli par bohaterów połączonych więzią romantyczną (związki te mogą być kanoniczne lub niekanoniczne); motywów, takich jak m.in. fluff, mpreg, PWP czy właśnie hurt/comfort; stosunku względem czasu akcji dzieła bazowego, tu m.in. prequele, sequele, ale także AU ( $\mathrm{z}$ ang. alternative universe) ${ }^{12}$.

7 Dane z 10.07.2020. https://archiveofourown.org/ [dostęp: 10.07.2020].

8 M. Lisowska-Magdziarz: Fandom dla początkujących. Kraków 2017, s. 127.

9 Ibidem, s. 127-128.

${ }^{10}$ K. Busse, K. Hellekson: Fan Fiction and Fan Communities..., s. 10.

${ }^{11}$ A. Kobus: Fandom. Fanowskie modele odbioru. Toruń 2018, s. 185.

${ }^{12}$ Teksty typu AU przedstawiają świat alternatywny wobec kanonu. Wykreowane przez fana w ramach AU zmiany mogą dotyczyć różnych aspektów dzieła źródłowego: czasu akcji (np. modern AU - postacie z danego okresu hi- 
Podział opierający się na formie dotyczy natomiast objętości tekstu, np. drabble - praca licząca dokładnie 100 słów, double drabble (lub double, droubble) - praca składająca się z 200 słów ${ }^{13}$.

Gen, het oraz slash to gatunki wyodrębnione pod względem występujących w tekście pairingów. Prace oznaczone jako gen nie skupiają się na uczuciowych, romantycznych czy seksualnych relacjach między bohaterami, osią fabuły nie są bowiem stosunki między postaciami. Fabuła het koncentruje się na pairingach wyróżnianych jako f/m (female/male - kobieta/mężczyzna), czyli na związkach heteroseksualnych, zarówno wykreowanych przez fana (tzn. niekanonicznych), jak i zawartych przez autora w dziele źródłowym ${ }^{14}$. Slash także skupia się na więziach (romantycznych, erotycznych) łączących postacie, ale są to relacje między osobami tej samej płci, przede wszystkim między mężczyznami, oznaczane jako $\mathrm{m} / \mathrm{m}$ (male) male - mężczyzna/mężczyzna). W wypadku par typu f/f (female/ female - kobieta/kobieta) popularniejszym określeniem jest femslash; $\mathrm{f} / \mathrm{f}$ slash zwykle traktowany jest jako odrębny gatunek. Slash najczęściej wykorzystuje związki niekanoniczne, czyli relacje bohaterów, którzy w utworze bazowym zostali sportretowani jako heteroseksualni lub których orientacja seksualna nie została sprecyzowana.

\section{slash a romans}

Przyjmuje się, że początki slashu sięgają końca lat 60. XX wieku. Nazwa gatunku wywodzi się od znaku ukośnika "/l" (ang. slash), którego używano w fandomie Star Treka przy oznaczaniu tekstów fanowskich, w których relacja między głównymi bohaterami serii (Kirkiem a Spockiem) ujmowana była jako romantyczna - wówczas oddzielano ich imiona symbolem ",l". Genezy slashu upatruje się m.in. w tym, że ówczesna oferta telewizyjna zawierała przede wszystkim narracje skoncentrowane wokół mężczyzn i występującej między nimi przyjaźni. Relacje romantyczne natomiast miały zwykle miejsce między głównym bohaterem a epizodyczną postacią żeńską i nie upatrywano w nich większego znaczenia zarówno dla fabuły, jak i protagonisty. Postacie kobiece, jeśli już się pojawiały, odgrywały zazwyczaj drugoplanowe role lub były skonstruowane w schema-

storycznego lub z przyszłości zostają przeniesione do współczesności), konkretnych wydarzeń (np. bohaterowie, którzy w kanonie umierają, zostają przy życiu), postaci (np. zmiana wykonywanej profesji; zmiana płci - tzw. genderswap).

13 A. Kobus: Fandom..., s. 185.

${ }^{14}$ K. Buse, K. Hellekson: Fan Fiction and Fan Communities..., s. 10. 
tyczny i mało interesujący sposób. Fanki włączały zatem w pisane przez siebie teksty męskich bohaterów, wykorzystując tym samym, obecne już $\mathrm{w}$ oryginale, silne więzi między nimi ${ }^{15}$. Dostrzegały potencjał romantyczny $\mathrm{w}$ sferze męskiej przyjaźni, kształtowanej w utworach kanonicznych odmiennie niż związki damsko-męskie, tzn. w sposób niebazujący przede wszystkim na atrakcyjności fizycznej, a na wspólnych doświadczeniach, relacjach opierających się na zaangażowaniu, zrozumieniu, lojalności, a także równości.

Slash przez wielu badaczy zestawiany jest z romansem. Niektórzy, np. Catherine Salmon i Don Symons ${ }^{16}$, akcentują elementy wspólne obu gatunków, proponując nawet traktowanie slashu jako jednego z podgatunków literackiego romansu. Inni, jak Anne Kustriz ${ }^{17}$, podkreślają występujące między nimi różnice. Nikt nie podważa jednak związku między tymi gatunkami.

Podstawowym podobieństwem jest skoncentrowanie na relacjach miłosnych między bohaterami. Charakterystyka postaci w slashu nie odpowiada jednak typowym cechom heroiny i herosa, ponieważ: po pierwsze - $w$ utworach tych mamy do czynienia $z$ dwoma męskimi bohaterami; po drugie - postacie $\mathrm{w}$ slashu są wyjęte $\mathrm{z}$ innych tekstów kultury. Generalnie więc bohaterowie slashu są bardziej zróżnicowani, a ich charakterystykę zasilają zwykle inne gatunki niż romans. Bardziej różnorodne są również schematy fabularne, tematy czy toposy wykorzystywane w slashu. Pewna powtarzalność spełnia się dopiero na płaszczyźnie pojedynczych, rozmaitych motywów. Istotnym elementem łączącym oba gatunki jest również to, że są pisane przede wszystkim przez kobiety dla innych kobiet ${ }^{18}$.

Bliskość fanfikcji z tradycyjnym pisarstwem kobiecym poruszyła Aleksandra Szymił w artykule Slash jako forma pisarstwa i czytelnictwa kobiecego $^{19}$. Szymił zwróciła uwagę, że badanie tekstów fanowskich, których autorkami i odbiorczyniami są w zdecydowanej większości kobiety, może stanowić istotny głos w dyskursie dotyczącym

15 A. Kobus: Fandom..., s. 44.

${ }^{16}$ C. Salmon, D. Symons: Slash Fiction and Human Mating Psychology. "The Journal of Sex Research" 2004, no 1, s. 94-100.

17 A. Kustritz: Slashing the Romance Narrative. „The Journal of American Culture" 2003, no 3, s. 371-384.

18 Traktowanie slashu jako pisarstwa ściśle związanego z kobietami zapoczątkował już tak naprawdę pierwszy tekst dotyczący tego zagadnienia, czyli esej Joanny Russ z 1985 roku zatytułowany Pornography by Women for Women, with Love pomieszczony w: Magic Mommas. Trembling Sisters. Puritans E Pervert. Ed. J. Russ. New York 1985, s. 79-99.

19 A. Szymiє: Slash jako forma pisarstwa i czytelnictwa kobiecego. „Teksty Drugie” 2015, nr 3, s. 117-134. 
pisarstwa i czytelnictwa tej grupy ${ }^{20}$. Stanowisko Szymił jest bliskie koncepcjom Henry'ego Jenkinsa, akcentującym kontestujący charakter aktywności fanów. Według polskiej badaczki fanfikcja jest formą twórczości skierowanej przeciwko patriarchalnej strukturze popkultury. Narracje realizowane w ramach slashu pozwalają wyjść poza dominujący dyskurs. Oprócz tego fanki poprzez slash dokonują rewizji pewnych problematycznych kwestii, m.in. stereotypów związanych z płcią ${ }^{21}$. Należy jednak pamiętać, że nie wszystkie teksty fanowskie reprezentują jednakowy potencjał krytyczny. Część z nich powstaje bowiem wyłącznie w celach rozrywkowych czy humorystycznych.

\section{hurt/comfort}

Fanowskie przekształcenia utworu wyjściowego mogą być różnorodne. Nie tylko pod względem wykorzystywanych motywów czasem bliskich tradycyjnym gatunkom literackim, ale również objętości czy stosunku do kanonu - niektóre teksty odrzucają go niemal całkowicie, inne oddają wiernie wiele jego elementów. Fanki włączają w część swoich narracji także to, co pozostaje często poza zainteresowaniem kultury głównego nurtu: choroby, cierpienie, śmierć. Zagadnienia te są poruszane przede wszystkim właśnie w tekstach hurt/comfort, które wyróżniają się tym, że jeden z głównych bohaterów ${ }^{22}$ składających się na dany pairing, zostaje fizycznie czy też psychicznie udręczony, a drugi otacza go opieką, zapewniając komfort i pocieszenie. Źródło cierpienia w tego typu tekstach zawsze znajduje się poza pairingiem. Ból, którego doświadcza postać, może mieć różną intensywność: od np. niegroźnego przeziębienia, po poważne choroby wymagające hospitalizacji (tzw. sickfic). Fanlore, internetowa encyklopedia dotycząca społeczności fanowskich, podaje, że wśród częstych motywów w ramach hurt/comfort znajdują się m.in.: amnezja, utrata wzroku, amputacja, paraliż, śpiączka, nowotwór, próba samobójcza, gwałt, tortury oraz różnego rodzaju zaburzenia psychiczne (np. zespół stresu pourazowego, depresja) ${ }^{23}$. W strukturze fabularnej, zwłaszcza w tzw. first time stories, cierpienie

${ }^{20}$ Ibidem, s. 118.

${ }^{21}$ Ibidem, s. 134.

${ }^{22}$ Niekoniecznie główny w odniesieniu do kanonu, może obejmować również postacie drugoplanowe.

${ }^{23}$ https://fanlore.org/wiki/Hurt/Comfort [dostęp: 28.06.2020]. 
służy zbliżeniu do siebie dwóch bohaterów, w przypadku slashu dwóch mężczyzn.

Na Archive of Our Own w ramach męskich pairingów znajduje się obecnie 217167 prac otagowanych jako hurt/comfort, w tym $440^{24}$ napisanych $\mathrm{w}$ języku polskim ${ }^{25}$. Teksty $\mathrm{w}$ obrębie archiwum publikowane są $\mathrm{w}$ ramach fandomów podzielonych na kilkanaście grup: filmy, teatr, programy telewizyjne, anime/manga, kreskówki/ komiksy/powieści graficzne, muzyka/zespoły, celebryci/rzeczywiste osoby, książki/literatura, gry komputerowe, inne media ${ }^{26}$. Najwięcej prac $\mathrm{w}$ gatunku hurt/comfort $\mathrm{w}$ języku polskim powstaje na podstawie: serii powieściowej o Harrym Potterze autorstwa J.K. Rowling, serialu Sherlock (2010-2017), serialu Nie z tego świata (2005-2020), serialu Teen Wolf: Nastoletni wilkołak (2011-2017) oraz filmów z uniwersum Marvela. Hurt/comfort jest wykorzystywany także $\mathrm{w}$ tekstach bazujących na polskiej literaturze. $W$ polskich fandomach literackich znajduje się obecnie jedenaście tekstów oznaczonych jako $\mathrm{H} / \mathrm{C}$, napisanych na podstawie takich utworów, jak m.in.: Lalka Bolesława Prusa (tu pairingi: Julian Ochocki/Stanisław Wokulski oraz Ignacy Rzecki/August Katz), Ludzie bezdomni Stefana Żeromskiego (pairing: Tomasz Judym/Korzecki). Ponadto polscy fani tworzą tego rodzaju opowieści $\mathrm{w}$ ramach gatunku RPF, dotyczące takich pisarzy jak: Adam Mickiewicz/Juliusz Słowacki (tzw. Słowackiewicz ${ }^{27}$ ), Zygmunt Krasiński/Juliusz Słowacki.

Częścią składową hurt/comfort, jak sama nazwa wskazuje, jest pocieszenie. Ból musi ostatecznie prowadzić do psychicznego i fizycznego ukojenia cierpiącego bohatera. Jeśli komponent komfortu zostaje pominięty czy też nie równoważy ukazanych udręk, mamy wówczas do czynienia z innym gatunkiem, określanym jako angst. Tego rodzaju teksty wypełnione są dramatyzmem, który nie zostaje zrekompensowany szczęśliwym zakończeniem. Cierpienia ukazywane w angst w mniejszym stopniu niż w hurt/comfort dotyczą cielesności, a większą rolę odgrywa tu zwykle kreowanie wewnętrznego świata postaci, wypełnionego głównie negatywnymi emo-

${ }^{24}$ Dane z 14.07.2020. https://archiveofourown.org/tags/Hurt* ${ }^{*}$ Comfort/works [dostęp: 14.07.2020].

${ }^{25}$ Sama strona internetowa dostępna jest jedynie w języku angielskim, umożliwia jednak publikowanie prac w różnych językach, których obecnie jest ponad 70, a wśród nich m.in. afrykanerski, arabski, bretoński, tajski, węgierski.

${ }^{26}$ https://archiveofourown.org/media [dostęp: 29.06.2020].

${ }^{27}$ Nadawanie nazwy dla pairingu z połączenia imion parowanych bohaterów jest częstą praktyką, np. Johnlock dla John Watson/Sherlock Holmes lub Spirk dla Spock/Kirk. 
cjami. Fabuła koncentruje się na przedstawieniach głębokiego lęku, smutku, niepokoju odczuwanego przez bohaterów, który z kolei ma wzbudzić podobne uczucia w czytelniku.

Jeden z ciekawszych polskich utworów stanowi Opium traktujące o relacji Stefana Żeromskiego i Kazimierza Przerwy-Tetmajera. Ten obszerny tekst - składający się z dziesięciu rozdziałów, liczący około 100 stron znormalizowanego maszynopisu (27 521 wyrazów) ${ }^{28}$ - nie opiera się na żadnym kanonie, ale w wielu miejscach nawiązuje do dzieł Żeromskiego i Przerwy-Tetmajera (m.in. cytaty z konkretnych utworów pisarzy jako motta rozdziałów, praca Żeromskiego nad Ludźmi bezdomnymi jako element fabuły itp.).

Akcja Opium rozgrywa się w Zakopanem, do którego Żeromski przyjeżdża w celu ratowania zdrowia. Spotyka tam Przerwę-Tetmajera, który jest nim zainteresowany nie jako pisarzem, lecz także jako mężczyzną. Struktura fabularna, choć nie zostało to zaznaczone w otagowaniu, realizuje schemat enemies to lovers ${ }^{29}$. Żeromski odczuwa bowiem początkowo niechęć do poety, przede wszystkim ze względu na jego dekadencką postawę. W tekście znajdują się odwołania do dzielących pisarzy różnic $w$ poglądach. Bohaterowie prowadzą liczne rozmowy, w których poruszają kwestie filozoficzne czy społeczne, prezentując przy tym zwykle sprzeczne stanowiska. Z czasem jednak wrogość Żeromskiego w stosunku do Przerwy-Tetmajera zaczyna współwystępować ze skrywaną fascynacją.

Układ ten przypomina jeden z przedstawionych przez Annę Martuszewską w Architektonice literackiego romansu wariantów ukazywania rozwoju uczuć, przebiegający od antypatii do pożądania ${ }^{30}$. Do konwencjonalnych motywów romansowych zaliczyć można również wątek z postacią kobiecą - rywalką, który pojawia się w momencie, gdy wydaje się, że bohaterowie ostatecznie będą razem. Żeromski błędnie odczytuje znajomość Przerwy-Tetmajera z kobietą i czując się

${ }^{28}$ Teksty publikowane na Archive of Our Own, ale także na innych stronach internetowych gromadzących fanfikcję, nie zawierają tożsamego z tekstami drukowanymi podziału na strony, ich objętość określana jest zazwyczaj poprzez liczbę słów i rozdziałów.

${ }^{29} \mathrm{~W}$ enemies to lovers relacje łączące postacie przechodzą od konfliktowych, pełnych niechęci czy nienawiści ku takim, które cechuje zrozumienie, sympatia, namiętność lub tylko namiętność - wrogowie stają się kochankami. Niektórzy fani stosują rozróżnienie na enemies to friends to lovers, gdy rozwój relacji postępuje od wrogości przez przyjaźń ku miłości oraz enemies to lovers, gdy pominięty zostaje etap zawiązywania przyjaźni i wrogość od razu prowadzi do romantycznej/erotycznej relacji.

30 A. Martuszewska: Architektonika literackiego romansu. Gdańsk 2014, s. 125. 
zdradzonym, wyjeżdża bez słowa z Zakopanego do swojego domu w Kielcach. Tu realizuje się kolejny, bliski tradycyjnemu romansowi motyw rozłąki i tęsknoty ${ }^{31}$ : „ściany zdawały się być od siebie oddzielone o kilometry, meble rozrzucone jak bezludne wyspy na morzu, a on płynął statkiem po oceanie pustki" ${ }^{\prime 32}$.

W Opium odnaleźć można także inne elementy charakterystyczne dla romansu, ale ujęte $\mathrm{w}$ niestereotypowy sposób. Od standardu odbiega np. opis pierwszego pocałunku, choć Żeromski (niczym przywoływana przez Martuszewską heroina z powieści sentymentalnej ${ }^{33}$ ) niemal mdleje: „poczuł dłoń Tetmajera na swoim krzyżu i, prawdę powiedziawszy, był mu wdzięczny, bo obawiał się, że spadnie bezwładnie na ziemię" ${ }^{\prime 34}$. Pocałunek ma jednak miejsce na etapie jeszcze nieuświadomionych uczuć, więc nie jest czymś, na co Żeromski czekał z utęsknieniem, a odczuwana przez niego przyjemność miesza się z niechęcią.

Odmienne jest także przedstawienie związku fizycznego. W wielu współczesnych romansach, jak zauważa Martuszewska, opis stosunku seksualnego ma wymiar niemal pornograficzny ${ }^{35}$. Tutaj jednak autorka pozostawiła tę kwestię w sferze domysłów. W rozdziale piątym Żeromski godzi się wejść do domu Przerwy-Tetmajera, gdzie „odrzuca zdrowy rozsądek” zaraz po tym, jak „czuł za sobą zimną ścianę sypialni, a na sobie ciepło drugiego ciała"36. Początek rozdziału szóstego zawiera jedynie opis przebudzenia się Żeromskiego następnego dnia, w nie swoim łóżku i w nie swojej koszuli. W kolejnych fragmentach pojawiają się wspomniane przeszkody - nieporozumienie związane $\mathrm{z}$ rywalką. $\mathrm{W}$ przedostatnim rozdziale dochodzi jednak do obustronnego i jednoznacznego wyznania miłości między pisarzami, które w tradycyjnym romansie prowadzi zwykle do małżeństwa lub nieformalnego zawiązania związku. W tym przypadku natomiast po wyznaniu uczuć bohaterowie rozstają się. Żeromski obawia się bowiem skandalu, nie wierzy też, że uda się ich relację utrzymać w tajemnicy.

Zamknięcie historii także odbiega od konwencji. Żeromski po prawie roku spędzonym w Kielcach wraca do Zakopanego i ponow-

\footnotetext{
31 Ibidem, s. 133.

32 https://archiveofourown.org/works/9873302?view_full_work=true [dostęp: 20.07.2020].

33 A. Martuszewska: Architektonika..., s. 127.

${ }^{34}$ https://archiveofourown.org/works/9873302?view_full_work=true [dostęp: 20.07.2020].

35 A. Martuszewska: Architektonika..., s. 134.

${ }^{36} \mathrm{https} / / /$ archiveofourown.org/works/9873302?view_full_work=true [dostęp: 20.07.2020].
} 
nie spotyka Przerwę-Tetmajera. Obaj wciąż są sobą zainteresowani. Autorka pozostawia jednak zakończenie otwarte. Ostatni dialog między postaciami kończy się znaczącym pytaniem skierowanym do Żeromskiego: „idziesz ze mną?". Odbiorca nie poznaje odpowiedzi. Dalsze losy bohaterów mogą więc mieć różne interpretacje.

Tekst utrzymany jest niemal $\mathrm{w}$ całości w stylistyce angstu, ale można odnaleźć w nim także elementy comfortu ${ }^{37}$, czego przykładem może być następująca scena:

Żeromski drżał z zimna. Tetmajer, słuchając jego słów, ściągnął długi gruby szalik i, gdy drugi mężczyzna przestał mówić, podszedł bliżej i zaczął owijać materiał wokół jego szyi. Pisarz nie wiedział, co zrobić, stał jakby zimno zamroziło go ostatecznie.

- Cóż pan znowu wyprawia...

- Jest panu zimno, prawda? Ja jestem przyzwyczajony, a pan musi na siebie uważać.

Stał za blisko. Żeromski czuł się wyjątkowo niekomfortowo, ciepły oddech poety docierał do jego zziębłej skóry. Nagle przypomniał sobie sen, który nawiedzał go ostatnimi czasy. Sen, który chciał wyprzeć z pamięci. Był to sen o ich ostatnim spotkaniu, które jednak zakończyło się trochę inaczej. Żeromski odwrócił wzrok od twarzy Tetmajera, pozwalając mu się owinąć szczelnie szalikiem. Gdy skończył, poeta wyjął z kieszeni parę rękawiczek i wcisnął je w lodowate ręce pisarza.

- To też proszę przyjąć. A w lesie jest wydeptana w śniegu ścieżka. Naprawdę, proszę mi zaufać choć trochę ${ }^{38}$.

Scenę tę poprzedza jeszcze inny, mający budzić w odbiorcy ciepłe uczucia, przejaw troski: Przerwa-Tetmajer wyprowadza z dusznego pomieszczenia Żeromskiego mającego atak kaszlu i zabiera go na spacer, aby poczuł się lepiej. Obie sytuacje zbudowane są zgodnie z poetyką hurt/comfort.

Autorka Opium nie skupia się wyłącznie na związku między głównymi postaciami. W tekście dużo miejsca zajmują również

${ }^{37}$ Należy zaznaczyć, że tekst został otagowany przez autorkę jako angst z elementami fluffu. Tego typu połączenie może odpowiadać w niektórych przypadkach gatunkowi hurt/comfort. Fluff to taki rodzaj fanfikcji, który nie zawiera skomplikowanej fabuły, stanowi zazwyczaj niedługą historię lub opis jednej sceny (choć może być także elementem większej całości). Fluff często koncentruje się na przejawach uczuciowości między postaciami, raczej pozbawionych erotyki. Może mieć również charakter humorystyczny. Najważniejsze jest stworzenie przyjemnej historii, która wywoła pozytywne emocje w czytelniku.

${ }^{38} \mathrm{https} / / /$ archiveofourown.org/works/9873302?view_full_work=true [dostęp: 20.07.2020]. 
obrazy przyrody oraz odwiedzanych przez Żeromskiego miejsc, m.in. zakopiańskiej restauracji. Opis panującej w niej atmosfery oddaje cechy charakterystyczne Młodej Polski, np. nastrój schyłku wieku. W utworze pojawiają się również inne -izmy epoki, takie jak dekadentyzm, marazm, hedonizm, a więc została ona wpisana przez autorkę jako fandom. Innymi słowy fanfik powstał przede wszystkim z ogólnego zainteresowania Młodą Polską i tworzącymi w tym okresie artystami (oprócz pary głównych bohaterów w Opium występują także: Stanisław Przybyszewski, Jan Kasprowicz oraz Władysław Reymont). Ma to prawdopodobnie związek z faktem, że utwór napisała osoba przygotowująca się do egzaminu maturalnego, co ujawniają otagowanie i przypisy końcowe.

\section{Intimatopia}

Mirna Cicioni określa gatunek hurt/comfort jako „erotyzację troski”. Czynności związane z zaspokajaniem podstawowych potrzeb osoby wymagającej opieki (takich jak np. ciepło, jedzenie, emocjonalne wsparcie) zyskują tu dodatkowe znaczenie. Zapewnianie komfortu przez bohatera, który nie jest cierpiący, temu, który doświadcza różnego rodzaju bólu, nabiera wymiaru erotycznego, ponieważ bliskość między nimi staje się fizyczna, co prowadzi do głębszej, bardziej intymnej relacji ${ }^{39}$. Podobnie $\mathrm{H} / \mathrm{C}$ charakteryzuje Elizabeth Woledge:

Hurt/Comfort zapewnia każdemu autorowi wiarygodny sposób ukazania wzrastającej bliskości pomiędzy dwoma mężczyznami, ponieważ ranny bohater jest najbardziej bezbronny. Ból pozwala mu dzielić się intymnością, która $\mathrm{w}$ innym przypadku pozostałaby ukryta ${ }^{40}$.

Dla Woledge najważniejszą kategorią w opisywaniu hurt/comfort, ale także całego slashu jest intymność. Z tym pojęciem wiąże się sformułowana przez badaczkę koncepcja intimatopii, czyli utopii intymności, do której zalicza m.in. fanowską twórczość literacką

${ }^{39}$ M. Cicioni: Male Pair-Bonds and Female Desire in Fan Slash Writing. In: Theorizing Fandom. Fans, Subculture, and Identity. Eds. C. Harris, A. Alexander. New Jersey 1998, s. 163.

${ }^{40}$ E. Woledge: Intimatopia: Genre Intersections Between Slash and the Mainstream. In: Fan Fiction and Fan Communities in the Age of Internet. Eds. K. BusE, K. Hellekson. Jefferson 2006, s. 110. Tłum. - M.S. 
w gatunku slash (obok oficjalnie wydanych powieści) ${ }^{41}$. Woledge $\mathrm{w}$ artykule Intimatopia: Genre Intersections Between Slash and the Mainstream wskazała także kluczową według niej różnicę pomiędzy romansem a slashem. W pierwszym intymność jest kształtowana głównie poprzez stosunki o charakterze erotycznym i nie występuje między bohaterami stale, lecz często jest jedynie chwilowa. W slashu natomiast intymność jest zwykle budowana przed stosunkiem seksualnym i utrzymywana dalej również po nim ${ }^{42}$. W opozycji do romantycznych tekstów kultury głównego nurtu intimatopie podkreślają, że to nie seks, a intymność napędza relacje międzyludzkie. Według Woledge właśnie $\mathrm{w}$ intymności, jako centralnej wartości w kontaktach interpersonalnych, objawia się subwersywność slashu. Fani w swoich pracach przejawiają zatem - jej zdaniem - pragnienie przywrócenia związku między miłością, przyjaźnią a intymnością ${ }^{43}$.

Woledge zauważa ponadto, że H/C pozwala kreować świat, w którym (w przeciwieństwie do typowego heteroseksualnego romansu) seks nie jest jedynym sposobem wyrażania zażyłości ${ }^{44}$, chociaż występująca w hurt/comfort czułość i opiekuńczość w wielu tekstach prowadzi do stosunku seksualnego. Umożliwia jednak opisanie również takich kontaktów fizycznych, które nie są bezpośrednio seksualne, a wciąż przedstawiają intymną relację między postaciami. Camille Bacon-Smith traktuje tę bliskość i komfort w H/C jako swego rodzaju substytut seksu, którego opisywanie sprawia niektórym autorom problem. Trudności te - jak zauważa badaczka - mogą wynikać m.in. z różnych ograniczeń społecznych, przykładowo związanych z homoseksualizmem, blokujących otwarte przedstawianie relacji między bohaterami tej samej płci ${ }^{45}$. Według Bacon-Smith kultura patriarchalna dopuszcza dwie sytuacje, w których możliwa jest emocjonalna i fizyczna bliskość między dorosłymi: ból i seks ${ }^{46}$. Jeśli drugi element nie może być z różnych przyczyn zrealizowany, zostaje wówczas zastąpiony. Sytuacje zagrażające życiu stają się zatem sposobem jawnego, także fizycznego, wyrażania skrywanych wcześniej uczuć, bez konieczności nadawania im wymiaru jednoznacznie erotycznego.

${ }^{41}$ Kobus zwraca uwagę, że odejście od rozdzielania slashu (i fanfikcji) jako osobnego segmentu produkcji kulturowej i wskazanie powiązań z mainstreamem (innych niż jedynie kontekst kanoniczny) stanowi istotny i największy wkład Woledge w fan studies. A. Konus: Fandom..., s. 264.

${ }^{42}$ E. Woledge: Intimatopia..., s. 106.

${ }^{43}$ Ibidem, s. 111.

${ }^{44}$ Ibidem.

${ }^{45}$ C. Bacon-Smith: Enterprising Women..., s. 256.

46 Ibidem. 
Bacon-Smith zwraca uwagę także na to, że H/C umożliwia autorkom i czytelniczkom przyjmowanie ról, które $\mathrm{w}$ androcentrycznej kulturze nie są zwyczajowo przypisywane kobietom. Badaczka wyróżniła obecną $\mathrm{w}$ większości tego typu tekstów triadę, na którą składają się: zewnętrzny (wobec pairingu) czarny charakter, powodujący ból, jeden z pary bohaterów, odczuwający cierpienie oraz drugi, zapewniający mu pocieszenie ${ }^{47}$. W przypadku H/C fanki nie muszą utożsamiać się jedynie z perspektywą opiekuna. Gatunek ten pozwala im zgłębiać wszystkie trzy role: „,mogą doświadczać gniewu poprzez postać zadającą ból, empatię i miłość poprzez pocieszyciela oraz zakłopotanie i strach ofiary ${ }^{\prime \prime 4}$.

Ponadto Bacon-Smith wskazuje, że fanki z pomocą H/C dokonują swoistej rekonstrukcji męskiego bohatera. Tego rodzaju ujęcie jest $\mathrm{w}$ pewnym stopniu zbieżne $\mathrm{z}$ interpretacjami slashu przedstawionymi przez Jenkinsa w książce Textual Poachers: Television Fans and Participatory Culture ${ }^{49}$. Według Jenkinsa slash reprezentuje sprzeciw wobec sposobów kształtowania męskiej tożsamości, seksualności $\mathrm{w}$ mediach ${ }^{50}$. Fanki poprzez slash prezentują alternatywne spojrzenie na męskie uczucia i emocje, tworzą odmienne dla kultury patriarchalnej wizje męskości:

Slash buduje narrację wokół zagadnienia męskości, próbuje stwarzać obrazy świata, w którym konwencjonalne tożsamości seksualne są zdefiniowane na nowo w bardziej płynny, mniej hierarchiczny sposób. Slash [...] zawiera wyraźną krytykę tradycyjnej męskości, stara się stwarzać homospołeczne-homoerotyczne kontinuum jako alternatywę dla represyjnej i hierarchicznej męskiej seksualnościin.

Teksty w odmianie H/C jeszcze wyraźniej realizują te założenia. Stereotypowo męskie wartości, przemoc i agresja, są tu zdecydowanie negowane. Siła, pozycja władzy wiążą się z cechami zwyczajowo uznawanymi za kobiece, typowo matczynymi wartościami: współczuciem, miłością, pielęgnacją oraz troską ${ }^{52}$.

Fanki-autorki stwarzają w swoich narracjach sytuacje, które uzupełniają pewne braki. Nie tylko w kontekście jednostkowego kanonu,

47 Ibidem, s. 270.

${ }^{48}$ Ibidem, s. 271.

${ }^{49}$ H. Jenkins: Textual Poachers: Television Fans and Participatory Culture. New York 1992.

${ }^{50}$ Ibidem, s. 194.

${ }^{51}$ Ibidem, s. 225.

52 C. Bacon-Smith: Enterprising Women..., s. 272. 
tzn. dopowiadając miejsca puste, które z perspektywy odbiorczyń stanowią najczęściej kwestie związane właśnie z intymnością, emocjami, czułością, czyli sferą uczuciowości i seksualności postaci. Ten brak można odnieść również do ogółu wytworów kultury głównego nurtu. Fanfikcja pokazuje, jakie elementy muszą być przez fanki negocjowane, co muszą napisać same, aby zwiększyć satysfakcję czerpaną z odbieranych utworów. Fanki zwracają uwagę na miejsca, z którymi się nie zgadzają i dokonują ich zmiany, przepisując zgodnie z własnymi oczekiwaniami. Kanon stanowi punkt wyjścia do ich własnych narracji, często znacząco odbiegających od treści zawartych w materiale źródłowym. Fanki przy użyciu hurt/comfort podważają tradycyjne wzorce męskości, demaskują ich ograniczenia, m.in. problem niemożności okazywania uczuć przez mężczyzn. Gatunek ten można więc traktować m.in. jako krytykę tzw. toksycznej męskości. Fanki zadają bohaterom rany (zarówno o charakterze fizycznym, jak i psychicznym) i pozwalają na otwarte doświadczanie cierpienia, słabości oraz lęku. Intensywne odczuwanie nie wiąże się wyłącznie z perspektywą udręczonego bohatera. Postać zapewniająca drugi z kluczowych elementów - comfort również doznaje silnych emocji. Kreowanie literackich obrazów wrażliwych mężczyzn dotyczy obu bohaterów składających się na dany pairing. Co ważne, ból w hurt/comfort nie jest bezcelowy - prowadzi do bliskości $\mathrm{i}$ intymności. Cierpienie opisywane w tego typu tekstach musi więc łączyć się z ukojeniem.

\section{Bibliografia}

BaCon-Smith C.: Enterprising Women. Television Fandom and the Creation of Popular Myth. Philadelphia 1992.

Busse K., Hellexson K.: Fan Fiction and Fan Communities in the Age of the Internet. New Essays. Jefferson, North Carolina 2006.

Cicioni M.: Male Pair-Bonds and Female Desire in Fan Slash Writing. In: Theorizing Fandom. Fans, Subculture, and Identity. Eds. C. Harris, A. Alexander. New Jersey 1998, s. 153-178.

Jenkins H.: Textual Poachers: Television Fans and Participatory Culture. New York 1992.

Koвus A.: Fandom. Fanowskie modele odbioru. Torun 2018.

Kobus A., Krzyżanowska J.: Stownik fandomu i fanfiction. W: Fandom. Fanowskie modele odbioru. Red. A. Kobus. Toruń 2018, s. 357-391.

Kustritz A.: Slashing the Romance Narrative. „The Journal of American Culture” 2003, no 3, s. 371-384.

LisowsKa-Magdziarz M.: Fandom dla początkujących. Kraków 2017. 
Martuszewska A.: Architektonika literackiego romansu. Gdańsk 2014.

Russ J.: Pornography by Women for Women, with Love. In: Magic Mommas. Trembling Sisters. Puritans \& Pervert. Ed. J. Russ. New York 1985, s. 79-99.

Salmon C., Symons D.: Slash Fiction and Human Mating Psychology. „The Journal of Sex Research" 2004, no 1, s. 94-100.

Szymiє A.: Slash jako forma pisarstwa i czytelnictwa kobiecego. "Teksty Drugie" 2015, nr 3, s. 117-134.

Woledge E.: Intimatopia: Genre Intersections Between Slash and the Mainstream. In: Fan Fiction and Fan Communities in the Age of Internet. Eds. K. Buse, K. Hellekson. Jefferson 2006, s. 97-115.

https://archiveofourown.org/ [dostęp: 10.07.2020].

https://archiveofourown.org/media [dostęp: 29.06.2020].

https://archiveofourown.org/tags/Hurt ${ }^{*}{ }^{*}$ Comfort/works [dostęp: 14.07.2020].

https://archiveofourown.org/works/9873302?view_full_work=true [dostęp:

20.07.2020].

https://fanlore.org/wiki/Hurt/Comfort [dostęp: 28.06.2020].

Marta Szpatowicz - doktorantka w Szkole Doktorskiej Uniwersytetu Szczecińskiego w dyscyplinie literaturoznawstwo. Obroniła pracę magisterską pt. Poetyka i pragmatyka slashu, napisaną na seminarium dr hab. Agaty Zawiszewskiej, prof. US.

e-mail: marta.szpatowicz@gmail.com 
